\title{
Poly(vinyl alcohol)/graphene oxide nanocomposites prepared by a simple eco-process
}

\author{
Seira Morimune ${ }^{1}$, Takashi Nishino ${ }^{1}$ and Takuya Goto ${ }^{2}$ \\ Graphene, a single layer of graphite, has recently attracted a large amount of attention because of its extremely high electronic \\ and thermal properties, as many nanoscale materials are based on individual graphene. Graphene oxide (GO), which is the \\ intermediate during the chemical processing of graphene, consists of graphene functionalized with oxygen-containing functional \\ groups that imparts the desirable solution-processability to the neat graphene. Herein, poly(vinyl alcohol) (PVA), a hydrophilic \\ polymer, was selected as the matrix, and PVA/GO nanocomposites were prepared by a simple and environment friendly \\ process using water as the proceeding medium. In the PVA matrix, GO was exfoliated and nanodispersed. We found that the \\ nanocomposites constructed by the incorporation of GO up to $1 \%$ by weight possess remarkable properties, such as significantly \\ high mechanical and thermal properties. These excellent reinforcement effects were achieved not only by the rigid structure \\ and high aspect ratio of the exfoliated GO but also by the strong interaction between PVA and GO. Furthermore, owing to \\ the sheet-like structure of GO, the barrier properties of the nanocomposites were found to be dramatically increased.
} Polymer Journal (2012) 44, 1056-1063; doi:10.1038/pj.2012.58; published online 18 April 2012

Keywords: barrier properties; graphene oxide; mechanical properties; nanocomposites; poly (vinyl alcohol)

\section{INTRODUCTION}

Nanotechnology is expected to make a major contribution to various industry fields that lead the way in the growth and development of the social economy. In recent years, many achievements were made by the newly stimulated research and development of nanotechniques. The initial discovery of nanocomposites, in which the filler has at least one dimension on the nanoscale, was reported by the Toyota Central R\&D Labs., Inc. (Aichi, Japan). ${ }^{1}$ They demonstrated that nylon6/clay nanocomposites showed a significant improvement in mechanical and thermal properties. ${ }^{2-4}$ Since then, much work has been dedicated to polymer nanocomposites. This work has revealed that these nanocomposites show remarkable material property enhancements, including mechanical properties, ${ }^{5,6}$ thermal properties ${ }^{7,8}$ and gas-barrier properties, ${ }^{9}$ compared with the virgin polymers or conventional micro filler-incorporated composites while using only a small amount of nanofillers.

In the last few decades, a variety of carbon-based nanomaterials, such as carbon nanotubes, have been used as nanofillers for polymer composites because of their outstanding properties. ${ }^{10,11}$ However, these materials have various problems including high costs, allegations against biosafety, low dispersibility in the polymer matrices and the blackening of the products. ${ }^{12}$ Therefore, the availability of carbon-based nanomaterials for polymer nanocomposites has been limited.

In 2004, single-layered two-dimensional graphene was first isolated by Novoselov et al.,13 at the University of Manchester, and they were consequently honored with the Nobel prize in 2010. Owing to the extremely high mechanical, electronic and thermal properties, nanoscale materials based on individual layers of graphene have recently attracted a great deal of attention. ${ }^{14-17}$ Great strides have been made in the use of solution-processable graphene materials for highly conducting composites, ${ }^{18-20}$ transparent electrodes ${ }^{21}$ and photovoltaic device applications. ${ }^{22,23}$ Currently, graphene, which is a perfect monolayer that does not exist naturally, can be produced in large quantities by the chemical reduction of graphene oxide (GO), using graphite as a raw material. ${ }^{24}$ Graphite is cheap and easily available, so this chemical approach is likely to be the simplest and most effective method for the large-scale production of graphene. GO, the intermediate formed during graphite chemical processing, consists of functionalized graphene with oxygen-containing functional groups, including hydroxyls, carboxyls, carbonyls and epoxides. These groups alter the van der Waals interactions between the graphene layers and impart the desired solution processablility. ${ }^{25-29}$ In addition, for polymer nanocomposites, the functional groups on the surface of graphene are expected to improve interfacial bonding between the graphene and the polymer matrices similar to conventional functionalized carbon-based nanomaterials used in reinforced polymer nanocomposites. ${ }^{30-32}$ These strong interactions between $\mathrm{GO}$ and the polymer matrices can be expected to significantly impart excellent reinforcement effects to the nanocomposite materials. In addition to exhibiting the aforementioned prominent properties, GO forms a unique sheet-like structure with a high aspect

${ }^{1}$ Department of Chemical Science and Engineering, Graduate School of Engineering, Kobe University, Kobe, Japan and ${ }^{2}$ Mitsubishi Gas Chem. Inc., Niijuku, Katsushika, Tokyo, Japan

Correspondence: Professor T Nishino, Department of Chemical Science and Engineering, Graduate School of Engineering, Kobe University, Rokko, Nada, Kobe, Hyogo 657-8501, Japan. 
ratio. Therefore, the nanodispersion of $\mathrm{GO}$ in the polymer matrices will impart not only the excellent properties of a carbonbased nanomaterial but also the unique properties of a sheet-like material.

In this study, we prepared the GO-reinforced polymer nanocomposites by a simple and environment friendly process. We selected poly(vinyl alcohol) (PVA), a hydrophilic polymer, as a matrix and used water as the solvent. The dispersibility of GO was examined with structural studies. The comprehensive investigation of the nanocomposites' properties, such as mechanical, barrier, thermal and optical properties, was carried out.

\section{EXPERIMENTAL PROCEDURE \\ Materials}

A $1 \mathrm{wt} \%$ GO aqueous suspension was supplied from Mitsubishi Gas Chemical, Inc. (Tokyo, Japan). The GO was synthesized from graphite utilizing Hummers' method. 25 PVA powder ('Gohsenol NH-18', Nippon Synthetic Chemical Industry Co., Ltd., Osaka, Japan) was used with a degree of polymerization of 1800 and a degree of saponification $>99 \%$.

\section{Sample preparation}

$P V A / G O$ nanocomposites. The PVA powder was dissolved in distilled water at $90{ }^{\circ} \mathrm{C}$ to obtain a $5 \mathrm{wt} \%$ PVA solution. The GO aqueous suspension was slowly added to the PVA solution under vigorous stirring to obtain a homogeneous $\mathrm{PVA} / \mathrm{GO}$ aqueous suspension. The GO content was varied to $0,0.1,0.5$ and $1 \mathrm{wt} \%$ against the amount of PVA powder. The PVA/GO aqueous suspensions were cast into glass petridishes, dried at room temperature and then dried in a vacuum at $40^{\circ} \mathrm{C}$ for $48 \mathrm{~h}$. The film thickness was controlled as $100 \mu \mathrm{m}$.

\section{Characterization}

The Fourier-transferred infrared spectrometery (Spectrum GX FT-IR System I-KS, Perkin Elmer, Waltham, MA, USA) was performed at a resolution of $2 \mathrm{~cm}^{-1}$. The accumulated number of scans was 10 . X-ray photoelectron spectroscopy (XPS) measurements were conducted for the GO powder on an indium ingot using an ESCA-850 spectrometer (Shimadzu Co., Kyoto, Japan) equipped with $\mathrm{MgK} \alpha$ radiation generated at $8 \mathrm{kV}$ and $30 \mathrm{~mA}$. X-ray diffraction was carried out with an X-ray diffractometer (RINT2100, Rigaku, Tokyo, Japan). The specimens were irradiated with an Ni-filtered $\mathrm{CuK} \alpha$ radiation beam operated at $40 \mathrm{kV}$ and $20 \mathrm{~mA}$. The scanning speed was 1.0 degree $\mathrm{min}^{-1}$, and the $2 \theta / \theta$ scan data were collected at 0.02 degree intervals. The crystallinity $\left(X_{\mathrm{c}}\right)$ of PVA was determined using the following equation

$$
X_{c}=\frac{A c}{(A c+A a)} \times 100
$$

where, $A c$ is the area of the crystalline region and $A a$ is the area of the amorphous region.

The tensile properties of the nanocomposites were evaluated using a tensile test with an Autograph AGS-1kND (Shimadzu Co.). The initial length of the specimen was $20 \mathrm{~mm}$, and a cross head speed of $2 \mathrm{~mm} \mathrm{~min}^{-1}$ was employed. The number of tested specimens exceeded ten. The toughness $(K)$, which is defined as the area surrounded by the stress $(\sigma)$-strain $(\varepsilon)$ curve, was calculated using the following equation

$$
K=\int_{\varepsilon=0}^{\varepsilon=\varepsilon_{\max }} \sigma \cdot d \varepsilon / \rho(J / g)
$$

where, $\sigma$ is stress $(\mathrm{Pa}), \varepsilon$ is strain $(\%)$ and $\rho$ is density $\left(\mathrm{g} \mathrm{m}^{-3}\right)$.

The dynamic mechanical analyses were performed using a dynamic mechanical analyzer, DVA-220 S (ITK Co., Ltd., Osaka, Japan), under nitrogen flow. A heating rate of $6^{\circ} \mathrm{C} \mathrm{min}^{-1}$ was employed with a frequency of $10 \mathrm{~Hz}$. The same analyzer was used to measure the humidity dependence of the storage modulus. The relative humidity (RH) was changed from $15 \% \mathrm{RH}$ to $90 \% \mathrm{RH}$ at a rate of $1 \% \mathrm{RH} \min ^{-1}$ in the air atmosphere at $60^{\circ} \mathrm{C}$.
The swelling ratio was determined by immersing the specimens in distilled water at $30^{\circ} \mathrm{C}$ and was defined as the weight gain of the specimens as follows

Swelling ratio $=W / W_{0}$

where, $W_{0}$ and $W$ is the weight of the specimen before and after swelling, respectively. The diffusion coefficient of water $(D)$ was determined using the following equation ${ }^{33,34}$

$$
D=\pi\left(\frac{Q r}{4}\right)^{2}\left(\mathrm{~m}^{2} / \mathrm{s}\right)
$$

where, $Q$ is the slope of the linear approximation obtained by plotting the swelling ratio versus the square root of the swelling time and $r$ is the thickness of the specimens.

Differential scanning calorimetry (DSC) was carried out using a differential scanning calorimeter (DSC-220CU, Seiko Instruments Inc., Chiba, Japan). The melting points $\left(T_{\mathrm{m}}\right)$ of the nanocomposites were determined as the endotherm peak temperature. The thermal decomposition temperature $\left(T_{\mathrm{d}}\right)$ was measured with a thermogravimeter (TG/DTA-220CU, Seiko Instruments Inc.). The $T_{\mathrm{d}}$ was defined as the temperature at which the substance had a $5 \mathrm{wt} \%$ thermal weight loss. DSC and thermogravimeter were performed under nitrogen flow with a heating rate of $10^{\circ} \mathrm{C} \mathrm{min}^{-1}$. The thermal expansion behavior was measured using a TMA/SS-120CU (Seiko Instruments Inc.) under nitrogen flow. The instrument was operated in tension mode under a $1 \mathrm{MPa}$ stress with a heating rate of $10^{\circ} \mathrm{Cmin}^{-1}$.

The ultraviolet-visible spectra were observed using a ultraviolet-visible spectrophotometer (U-2000, Hitachi Ltd., Tokyo, Japan) at a wavelength scan rate of $400 \mathrm{~nm} \mathrm{~min}^{-1}$

\section{RESULTS AND DISCUSSION Characterization}

The Fourier-transferred infrared spectrum of GO is shown in Figure 1a. The spectrum shows the characteristic absorption bands of GO. The band at $1622 \mathrm{~cm}^{-1}$ can be assigned to the stretching vibration of an aromatic $\mathrm{sp}^{2}$ carbon bond. The bands at $\sim 2915 \mathrm{~cm}^{-1}$ and $1352 \mathrm{~cm}^{-1}$ are attributed to aliphatic $\mathrm{C}-\mathrm{H}$ stretching and deformational vibration, respectively. ${ }^{35}$ In addition to the bands derived from the structure of graphene, which are planar sheets of $\mathrm{sp}^{2}$-bonded carbon atoms, the oxygen-containing functional groups were also observed. The bands at $1733 \mathrm{~cm}^{-1}, 1225 \mathrm{~cm}^{-1}$ and $1075 \mathrm{~cm}^{-1}$ can be assigned as $\mathrm{C}=\mathrm{O}$ stretching, $\mathrm{C}-\mathrm{OH}$ bending and $\mathrm{C}-\mathrm{O}$ stretching, respectively. ${ }^{36}$ Furthermore, the band at $975 \mathrm{~cm}^{-1}$ can be assigned as the symmetrical epoxy ring deformation as well as the out-of-plane wagging of $\mathrm{O}-\mathrm{H}-\mathrm{O} .{ }^{37}$ The hydroxyl groups appeared at $3404 \mathrm{~cm}^{-1}(\mathrm{O}-\mathrm{H}$ stretching vibration) and $1622 \mathrm{~cm}^{-1}$ (O-H bending vibration), which included adsorbed water on the GO surface in air. ${ }^{38,39}$ To confirm the presence of the oxygen-containing groups on the surface of GO, XPS measurements were conducted.

Figures $1 \mathrm{~b}-\mathrm{d}$ shows the atomic $\%$ and ratio O/C from the XPS analysis (panel b), C1s (panel c) and O1s spectra of GO (panel d). From Figure 1b, the XPS analysis revealed that GO contains $27.8 \%$ oxygen, which can be related to the oxygen-containing groups discussed in detail below. Figure 1c represents the C1s spectrum that is essentially composed of five peaks, which clearly indicate the existence of different types of functional groups. The peaks at $289.1 \mathrm{eV}$ (peak 1) and $289.9 \mathrm{eV}$ (peak 2) can be assigned as carbonyl groups and carboxyl groups, respectively. ${ }^{40,41}$ The peak for the C-O$\mathrm{C}$ bond in epoxies/ethers as well as that for $\mathrm{C}-\mathrm{OH}$ bonding were found at the binding energy of $287.5 \mathrm{eV}$ (peak 3). ${ }^{42}$ The peaks related to the graphene components appeared at $284.5 \mathrm{eV}\left(\mathrm{sp}^{3}\right.$ carbons and alkyl groups) (peak 4) and $283.7 \mathrm{eV}$ (graphitic $\mathrm{sp}^{2}$ carbon species) (peak 5). ${ }^{43}$ For the Ols spectrum, the peaks are curve resolved into three Gaussian peaks (Figure 1d). The peak from hydroxyl groups 
a

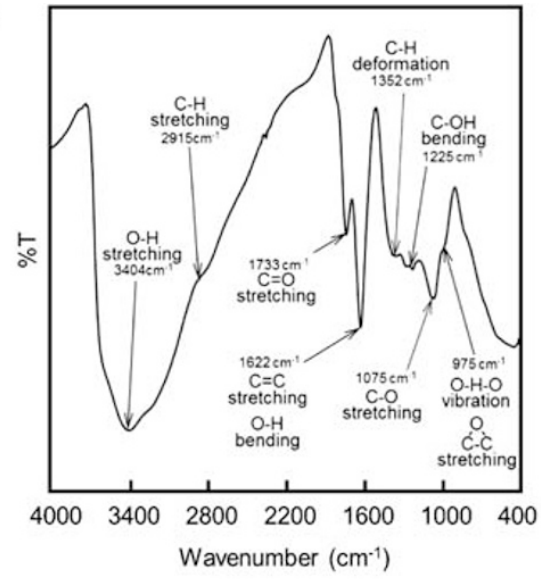

C

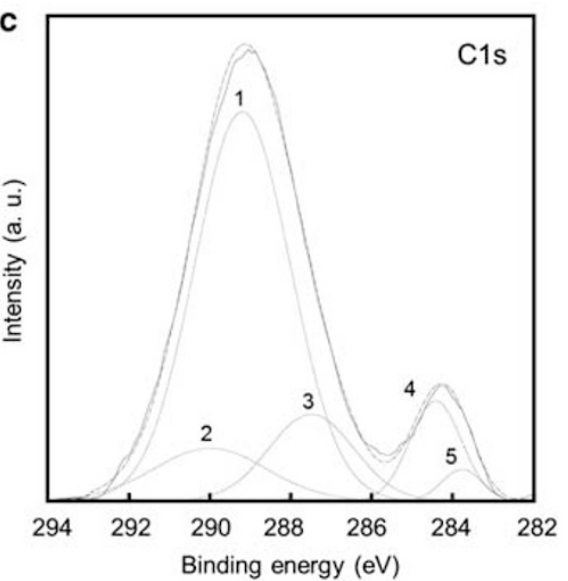

b

\begin{tabular}{cccc}
\hline & \multicolumn{2}{c}{ atom $\%$} & ratio \\
\cline { 2 - 4 } & $\mathrm{C}$ & $\mathrm{O}$ & $\mathrm{O} / \mathrm{C}$ \\
\hline $\mathrm{GO}$ & 72.2 & 27.8 & 0.39 \\
\hline
\end{tabular}

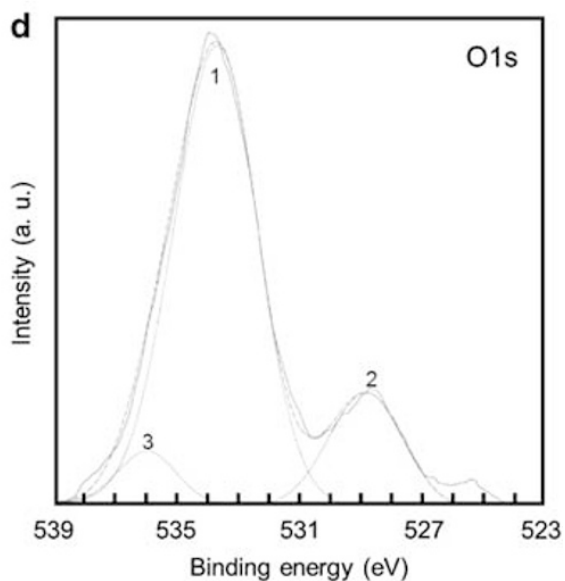

Figure 1 (a) FT-IR spectrum of GO; (b) atomic \% and O/C ratio of GO from the XPS analysis; (c) C1s XPS spectrum of GO; (d) O1s XPS spectrum of GO.

was observed as the most intense peak, at $533.6 \mathrm{eV}$ (peak 1). The peak at $528.5 \mathrm{eV}$ can be related to carboxyl/carbonyl/ether groups (peak 2), and the peak at $536.0 \mathrm{eV}$ can be related to a nepoxy group (peak 3). ${ }^{41}$ Judging from the results of XPS and those of the Fouriertransferred infrared (Figure 1a), the surface of GO was oxidized adequately, which resulted in the nanodispersion of GO in an aqueous medium.

Figure 2 shows the X-ray diffraction profiles of the PVA film, PVA/ GO nanocomposites and GO powder dried from aqueous medium. The characteristic peak for GO appeared clearly at $2 \theta=10.1^{\circ}$, which can be assigned as the 001 reflection corresponding to the graphite interlayer distance. Because GO-formed agglomerates during drying, the reflection assigned as this interlayer appeared. This 001 reflection was also observed for the profile of the PVA/GO mixture, for which the PVA and GO powders were physically mixed using a mortar, overlapping with the 100 reflection of PVA. On the other hand, for the nanocomposites this reflection disappeared, which suggests that GO was well exfoliated and homogeneously dispersed in the PVA matrix. $^{44,45}$ The SEM photograph of the cross section of the nanocomposite also shows that the GO sheets were nano-dispersed. In addition, the GO sheets were partially oriented parallel to the film surface (Supporting Figure S2). The $X_{\mathrm{c}}$ values determined by the X-ray diffraction profiles were found to increase from $28 \%$ in a neat PVA film to 30,33 and $35 \%$ by the incorporation of $0.1,0.5$ and $1 \mathrm{wt} \%$ GO loading, respectively. Many reports have described the incorporated inorganic filler acting as crystallization nuclei. Thus, GO was considered to act as the crystallization nucleus of the PVA matrix. ${ }^{2,7}$

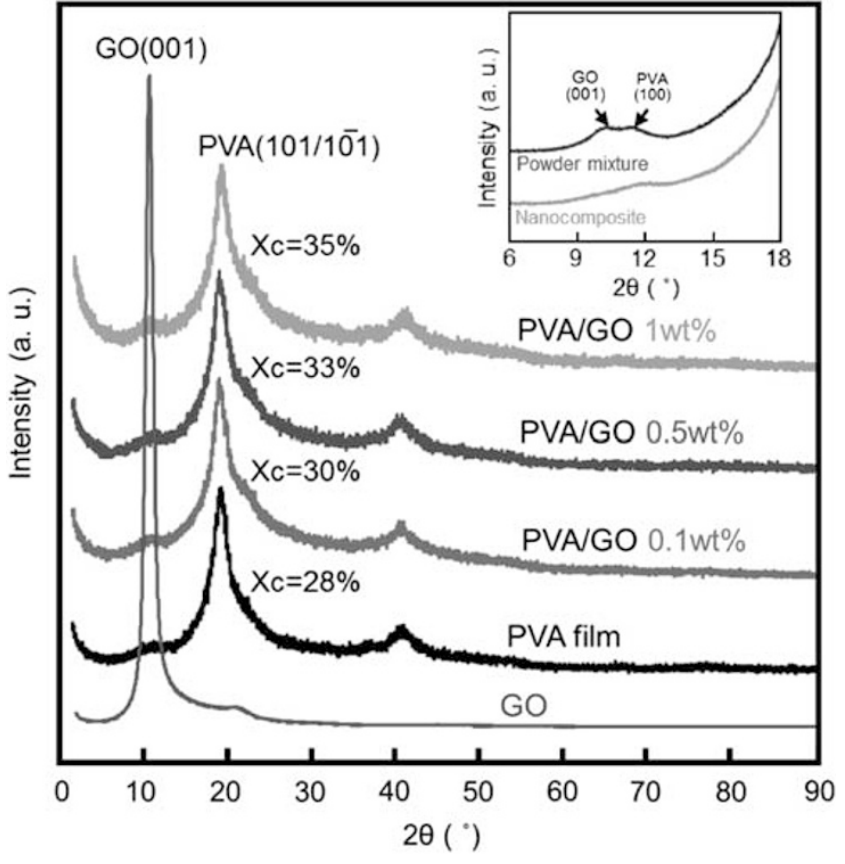

Figure 2 X-ray diffraction profiles of the PVA film, the PVA/GO nanocomposites and GO. The figure inserted on the upper right is the profiles of the PVA/GO nanocomposite and the physical mixture of PVA/GO powder with 1 wt $\%$ GO loading. A full color version of this figure is available at Polymer Journal online. 

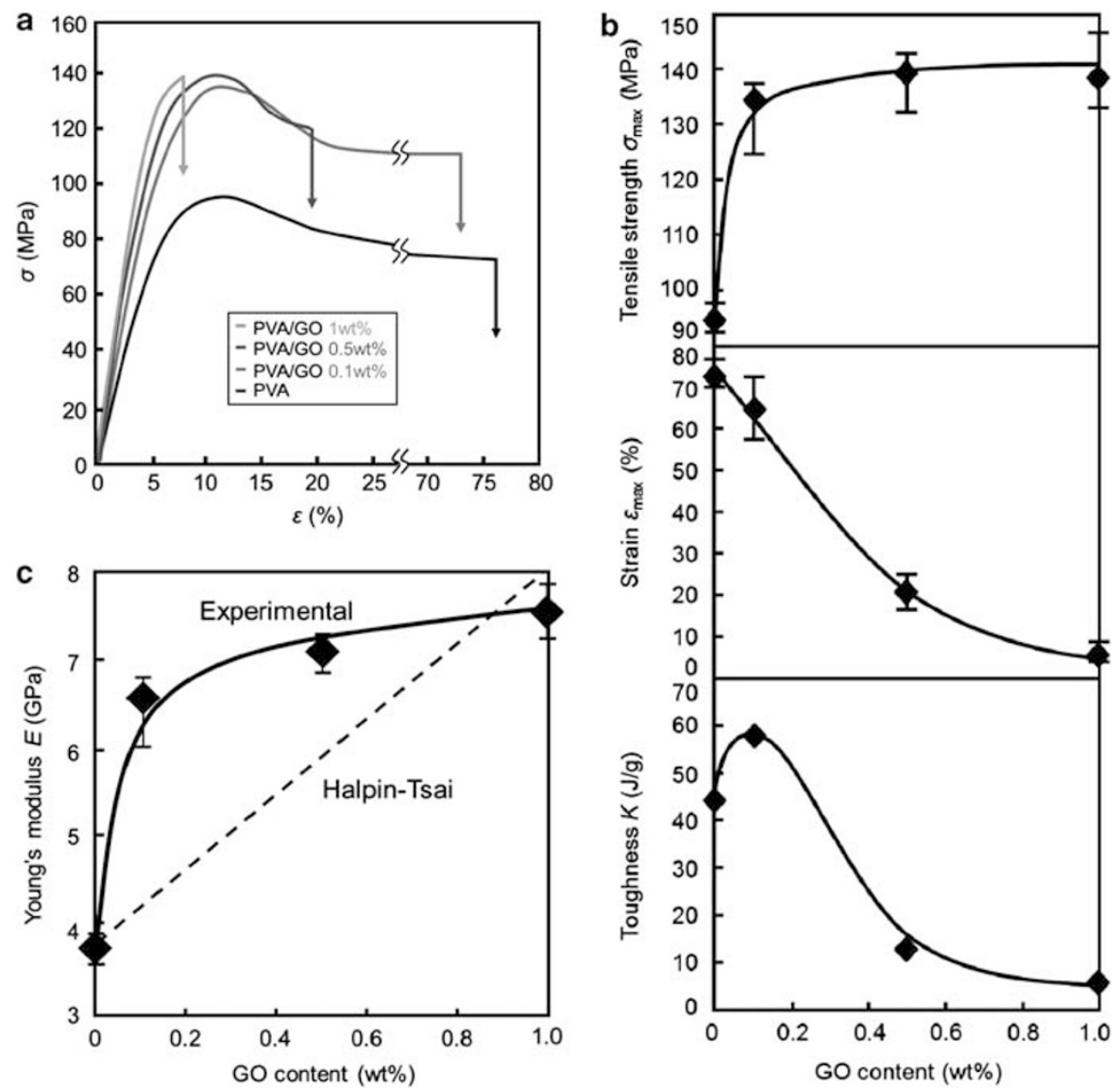

Figure 3 (a) Stress $(\sigma)$-strain $(\varepsilon)$ curves of the PVA film and the PVA/GO nanocomposites; (b) Experimental tensile strength $\left(\sigma_{\max }\right)$, strain $\left(\varepsilon_{\max }\right)$ and toughness ( $K$ ) of the PVA/GO nanocomposites; (c) Experimental Young's modulus $(E)$ of the PVA/GO nanocomposites and the calculated data derived from the Halpin-Tsai equation. A full color version of this figure is available at Polymer Journal online.

\section{Mechanical properties}

Figure 3a shows the stress $(\sigma)$-strain $(\varepsilon)$ curves of the PVA film and the PVA/GO nanocomposites. The tensile strength $\left(\sigma_{\max }\right)$, equal to the yielding stress, and Young's modulus $(E)$ dramatically increased by the incorporation of GO. Conversely, the elongation at the break $\left(\varepsilon_{\max }\right)$ of the nanocomposites decreased with an increasing GO content, whereas the PVA film showed the typical $\sigma-\varepsilon$ curve for a conventional polymer film with yielding. Figure $3 \mathrm{~b}$ shows the relationship between the GO content and $\sigma_{\max }, \varepsilon_{\max }$ and the $K$ of the PVA film and the PVA/GO nanocomposite (see also Supporting Table S1). The fracture of the composites would be caused by the strong but brittle nature of GO and the aggregation of GO, which can be the starting point of the crack under concentrated stress. However, for the nanocomposites with $0.1 \mathrm{wt} \%$ GO loading, the high $\varepsilon_{\max }$ close to that of the PVA film remained. Therefore, the $K$ value of the nanocomposites with $0.1 \mathrm{wt} \%$ GO loading increased 33\% higher than that of the PVA film. This result shows that the nanodispersion of GO was successfully achieved with $0.1 \mathrm{wt} \%$ loading of GO. Zhao et al., ${ }^{46}$ reported that the slippage of graphene nanosheets during the tensile testing had a role in the suppression of the rapid decrease of $\varepsilon_{\max }$. It can be assumed that as extra GO was added into the PVA matrix, the interaction between the GO sheets, mainly by van der Waals force, would stack the sheets together and form large GO agglomerates. Therefore, with excess GO loading, brittle failure can easily occur in the nanocomposites, and as a result, the $K$ value drastically decreases.
Figure $3 \mathrm{c}$ shows the relationships between the $E$ and GO content of the PVA/GO nanocomposites (see also Supporting Table S1). The E of the nanocomposite increased drastically to $176 \%$ compared with the $E$ of the PVA film with only $0.1 \mathrm{wt} \%$ GO loading. In the past, many theoretical and empirical models have been developed for polymer composite systems. ${ }^{47-52}$ A comparison was made between the experimental data and the model predictions for the PVA/GO nanocomposites. Here, we employed the Halpin-Tsai equations, which are the most widely used model to estimate reinforcement effect of filler in composites, based on the assumption that the GO sheets were aligned parallel to the surface of the composite films. The equations are given as follows

$$
\begin{gathered}
E_{\mathrm{c}}=E_{\mathrm{m}} \frac{\left(1+\eta \xi V_{\mathrm{f}}\right)}{\left(1-\eta V_{\mathrm{f}}\right)} \\
\eta=\frac{\left(E_{\mathrm{f}} / E_{\mathrm{m}}-1\right)}{\left(E_{\mathrm{f}} / E_{\mathrm{m}}+\xi\right)}
\end{gathered}
$$

where, $E_{\mathrm{c}}, E_{\mathrm{f}}$ and $E_{\mathrm{m}}$ are the $E$ of the composite, filler and matrix, respectively, and $V_{\mathrm{f}}$ is the volume fraction of filler. $\xi$ is a shape parameter that depends on filler geometry, orientation and loading direction and is equal to the following equation

$$
\xi=\frac{2 \alpha_{\mathrm{f}}}{3}=\frac{2 l_{\mathrm{f}}}{3 t_{\mathrm{f}}}
$$


where, $l_{\mathrm{f}}$ and $t_{\mathrm{f}}$ are the length and thickness of GO, respectively. The average size of GO was determined from $>20$ of the atomic force microscope (AFM) images. Monolayers of GO were observed with an average size of $l_{\mathrm{f}}=3 \mu \mathrm{m}$ and $t_{\mathrm{f}}=1 \mathrm{~nm}$ (Supporting Information; Figure 1). The $E_{\mathrm{c}}$ values of the PVA/GO nanocomposites were calculated using the above equations 5-7 and are shown with a roken line in Figure 3c. For the nanocomposites with a low GO content (under $1 \mathrm{wt} \%$ ), the experimental $E$ value greatly exceeded the model predictions. These unrivaled reinforcement effects can be achieved by the combination of several elements in the PVA/GO nanocomposites. First, as previously mentioned in Figure 2, the $X_{c}$ of the PVA matrix increased with increasing GO content. Therefore, the mechanical properties of the PVA matrix increased, which contributes to the enhancement of the mechanical properties of the nanocomposites. The strong interfacial interaction between PVA and GO also supplies a reinforcement effect. ${ }^{44,45}$

Scheme 1 shows the schematic illustration of the possible interactions between PVA and GO. There are oxygen-containing moieties, such as hydroxyl, carbonyl, carboxyl, ether and epoxy groups, on the surface of GO, as shown in the results from the Fourier-transferred infrared and XPS (Figures 1a-d). These groups can form hydrogen bonds with PVA. Furthermore, because of the large aspect ratio of GO, which was exfoliated and nanodispersed in the PVA matrix, the strong interaction was achieved at the interface between the PVA matrix and GO. Therefore, the excellent mechanical properties that exceeded the predictions could be achieved for the PVA/GO nanocomposites.

Figure $4 \mathrm{a}$ shows the temperature dependence of the storage modulus $\left(E^{\prime}\right)$ and the mechanical $\tan \delta$ of the PVA film and the

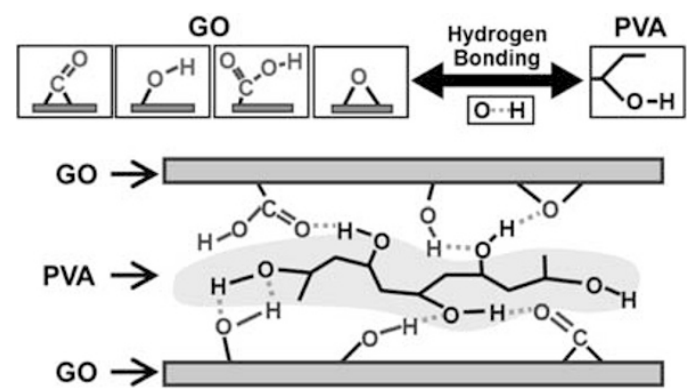

Scheme 1 Schematic illustration of the possible interaction between PVA and GO. A full color version of this scheme is available at Polymer Journal online.
PVA/GO nanocomposites. The main dispersion in $\tan \delta$, the so-called $\alpha_{\mathrm{a}}$, was $\sim 61{ }^{\circ} \mathrm{C}$ and is assigned as the glass transition $\left(T_{\mathrm{g}}\right)$ of the PVA matrix. ${ }^{53}$ By the incorporation of GO, the peak of this dispersion shifted to higher temperatures, and at the same time the intensity of the peak decreased. The other dispersion at $\sim-5^{\circ} \mathrm{C}$, the so-called $\beta$ dispersion was also suppressed by the GO loading. From the dynamic mechanical analysis over the glass transition temperature $\left(T_{\mathrm{g}}\right)$ of PVA, the decrease of $E^{\prime}$ with temperature was effectively suppressed by the incorporation of $\mathrm{GO}$, and the high $E^{\prime}$ was maintained within the entire temperature range (from $-150{ }^{\circ} \mathrm{C}$ to $200^{\circ} \mathrm{C}$ ) for the PVA/GO nanocomposites. ${ }^{54}$ These results indicate that the molecular motion of the polymer chains was restricted in the amorphous phase of PVA by the interactions between the GO nanosheets and/or PVA and GO, causing sufficient reinforcement effects. ${ }^{32,55-59}$ Furthermore, the dynamic mechanical analysis results revealed that the high $E^{\prime}$ value was maintained even under a high $\mathrm{RH}$ in the range of $15-90 \%$ at $60^{\circ} \mathrm{C}$ (Figure $4 \mathrm{~b}$ ). The arrow indicates the maximum QUOTE, which shifted to a high temperature with GO loading. Because the nanodispersion of GO has a high aspect ratio, the penetration pass of water in the PVA matrix was considered to be prolonged, and the relaxation of the PVA molecular chains was suppressed. Furthermore, in the nanocomposites, the GO sheets were partially oriented parallel to the film surface (Supporting Figure S2), which prevented the penetration of humidity. This phenomenon in the high $\mathrm{RH}$ can also be explained as a barrier property as shown below.

\section{Barrier properties}

Figure 5a shows the swelling ratio of the PVA film and the PVA/GO nanocomposites in distilled water at $30^{\circ} \mathrm{C}$. Subsequently, the dotted line in the figure shows the swelling ratio of the fluorinated PVA film reported previously, where the PVA film surface was chemically modified with a fluorinated silane-coupling agent. ${ }^{60}$ The PVA film showed a high swelling ratio because of its water olubility. Alternatively, for the PVA/GO nanocomposites with only $0.1 \mathrm{wt} \%$ GO loading, the plateau swelling ratio was suppressed 55\% compared with that of the PVA film, which is comparable to the fluorinated PVA film. Judging from the gradient of the swelling curve, the incorporation of $1 \mathrm{wt} \%$ GO into the PVA matrix prevented the penetration of water into the bulk similar to that of the fluorination of the PVA film. The diffusion coefficients of water for the PVA film and the PVA/GO nanocomposites are shown in Figure 5b. The diffusion coefficient of the nanocomposites with only $1 \mathrm{wt} \%$ of GO
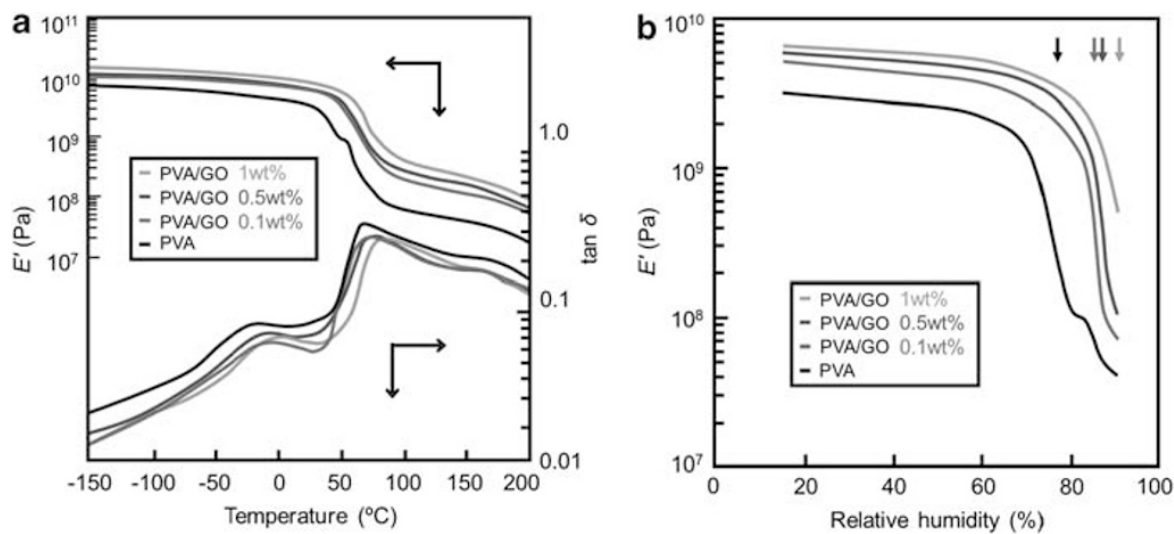

Figure 4 (a) Temperature dependence of the storage modulus $\left(E^{\prime}\right)$ and the mechanical tan $\delta$ of the PVA film and the PVA/GOnanocomposites; (b) RH dependence of $E^{\prime}$ for the PVA film and the PVA/GO nanocomposites at $60^{\circ} \mathrm{C}$. A full color version of this figure is available at Polymer Journal online. 

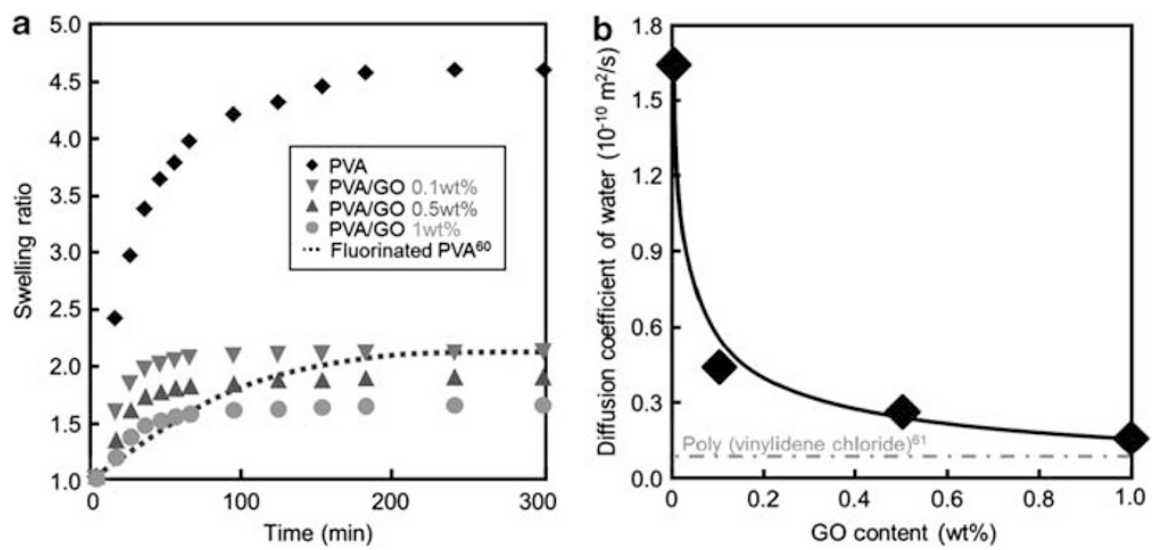

Figure 5 (a) Swelling ratio of the PVA film and the PVA/GO nanocomposites with water at $30^{\circ} \mathrm{C}$. The results for the fluorinated PVA film was superimposed as a dotted line; 60 (b) water diffusion coefficient for the PVA film and the PVA/GO nanocomposites. The broken line is that of poly (vinylidene chloride). ${ }^{61}$ A full color version of this figure is available at Polymer Journal online.
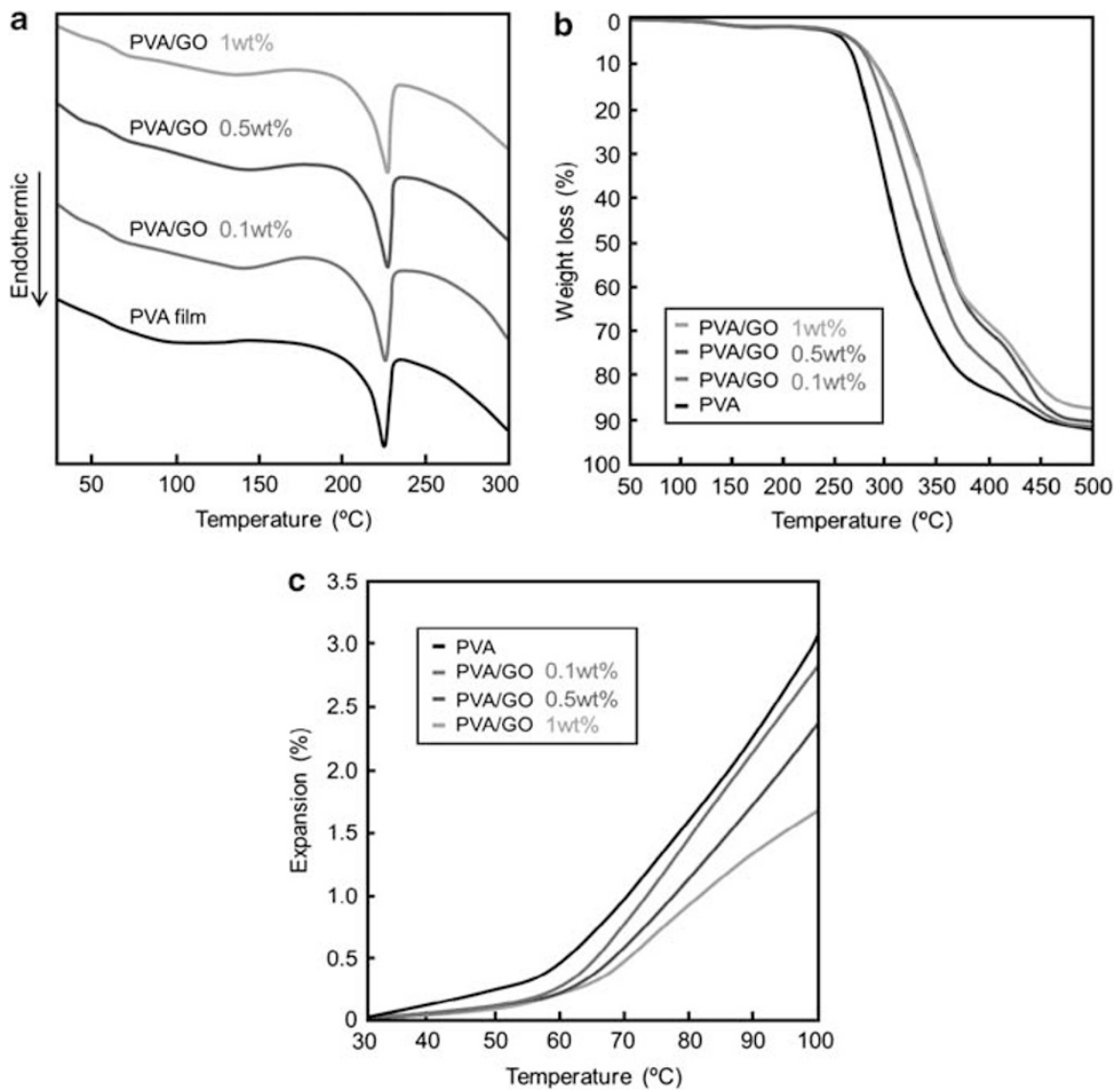

Figure 6 (a) Differential scanning thermograms of the PVA film and the PVA/GO nanocomposites; (b) thermogravimetric traces of the PVA film and the PVA/GO nanocomposites. (c) Thermal expansion behavior of the PVA film and the PVA/GO nanocomposites under $1 \mathrm{MPa}$. A full color version of this figure is available at Polymer Journal online.

$\left(1.3 \times 10^{-11} \mathrm{~m}^{2} \mathrm{~s}^{-1}\right)$ was comparable to that of poly(vinylidene chloride) $\left(1.0 \times 10^{-11} \mathrm{~m}^{2} \mathrm{~s}^{-1}\right),{ }^{61}$ which is well known for its high barrier properties. Therefore, as described above in the results of dynamic mechanical analysis (Figures $4 \mathrm{a}-\mathrm{b}$ ), the high dispersibility and the sheet-like structure of GO was effectively imparted to the nanocomposites, and the excellent barrier property of the nanocomposites against water was achieved, despite the water-swellable nature of the PVA matrix.

\section{Thermal properties}

Figure 6a shows the DSC thermograms of the PVA film and the PVA/GO nanocomposites. The endotherm assigned as the $T_{\mathrm{m}}$ of pure PVA $\left(\sim 225^{\circ} \mathrm{C}\right)$ was clearly observed in every case. The $T_{\mathrm{g}}$ and $T_{\mathrm{m}}$ of the PVA film and the PVA/GO nanocomposites are summarized in Table 1. The increase in the $T_{\mathrm{g}}$ caused by the incorporation of GO was observed in the DSC thermograms, which coincide with the results of dynamic mechanical analysis (Figure 4a). 
There was no obvious change in $T_{\mathrm{m}}$ by the incorporation of GO. This result suggests that GO largely affects the amorphous region but has almost no effect on the crystalline regions of the PVA matrix.

The thermogravimetric traces further used to characterize the thermal properties of PVA and the PVA/GO nanocomposites are shown in Figure $6 \mathrm{~b}$. The onset temperature of the thermal degradation $\left(T_{\mathrm{d}}\right)$ of the nanocomposite increased gradually by the incorporation of GO (Table 1). The $T_{\mathrm{d}}$ of the PVA/GO nanocomposite with $1 \mathrm{wt} \%$ GO loading was $8{ }^{\circ} \mathrm{C}$ higher than that of PVA film. This result indicates that, owing to the nanodispersion and its high aspect ratio, GO can act as a barrier to hinder not only water adsorption (Figure 5) but also the volatile decomposition products throughout the nanocomposites. ${ }^{62}$ In addition, the PVA molecular motion was suppressed by the rigid structure of the GO nanosheets, which have been ascribed to the stability of the hydrogen bonding between PVA and GO that improves the thermal stability of PVA. ${ }^{32}$

The dimensional stability was evaluated by the measurement of the thermal expansion behavior of PVA film and the PVA/GO nanocomposites (Figure 6c). For wide applications of the composites, warping and other changes in shape during the service should be avoided, and the dimensional stability is critical. The thermal expansion was suppressed steadily by loading with GO. From Figure 6c, it is apparent that the heat distortion temperature increased with increasing GO content. The heat distortion temperature of the PVA/GO nanocomposite with $1 \mathrm{wt} \%$ GO loading was $66^{\circ} \mathrm{C}$, which is $8{ }^{\circ} \mathrm{C}$ higher than that of the PVA film. The thermal expansion coefficients

Table 1 Thermal properties of the PVA film and the PVA/GO nanocomposites

\begin{tabular}{lccccc}
\hline & $\mathrm{T}_{g}$ & $\mathrm{~T}_{m}$ & $\mathrm{~T}_{d}$ & $\alpha\left(40-50^{\circ} \mathrm{C}\right)$ & $\alpha\left(80-90^{\circ} \mathrm{C}\right)$ \\
\cline { 2 - 6 } & ${ }^{\circ} \mathrm{C}$ & ${ }^{\circ} \mathrm{C}$ & ${ }^{\circ} \mathrm{C}$ & $10^{-5} \mathrm{~K}^{-1}$ & $10^{-4} \mathrm{~K}^{-1}$ \\
\hline PVA & 62 & 225 & 263 & 8.8 & 6.9 \\
PVA/GO 0.1 wt\% & 65 & 225 & 265 & 7.2 & 5.9 \\
PVA/GO 0.5 wt\% & 68 & 226 & 269 & 5.9 & 4.0 \\
PVA/GO 1 wt\% & 76 & 227 & 271 & 4.7 & 2.1 \\
\hline
\end{tabular}

Abbreviations: GO, graphene oxide; PVA, poly(vinyl alcohol); $T_{\mathrm{d}}$, thermal decomposition temperature; $T_{\mathrm{g}}$, glass transition temperature; $T_{\mathrm{m}}$, melting points.

a

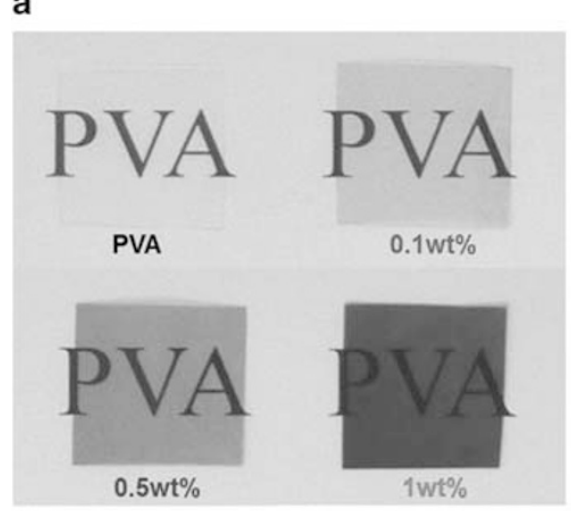

$(\alpha)$ between $40-50{ }^{\circ} \mathrm{C}$ and $80-90{ }^{\circ} \mathrm{C}$ of the PVA film and the PVA/GO nanocomposites are summarized in Table 1 . In both cases, the $\alpha$ value of the nanocomposites decreased linearly with the loading of GO. Especially above $T_{\mathrm{g}}$, the $\alpha$ value was drastically suppressed by the incorporation of GO. This result is likely because of the distribution of GO, which suppressed the PVA molecular motion, and because the rigid structure of GO was sufficiently imparted to the nanocomposites.

\section{Optical transparency}

The optical images of the PVA film and the PVA/GO nanocomposites are shown in Figure 7a. Following the incorporation of GO, the nanocomposites slightly turned pale brown. Figure $7 \mathrm{~b}$ shows the ultraviolet-visible spectra of the PVA film and the PVA/GO nanocomposites. Across the visible light region of the wavelength of $380-780 \mathrm{~nm}$, the PVA film exhibited a high transparency of $>90 \%$, which enables PVA to be used as an optical film such as a polarizer. On the other hand, for the nanocomposites, the transparency decreased with increasing GO content. Thus, the transparency to opacity of the nanocomposites is controllable simply by changing the content of GO.

\section{CONCLUSION}

We prepared the PVA/GO nanocomposites using a simple casting method from an aqueous medium. From the structural studies, GO was revealed to be exfoliated and nanodispersed in the PVA matrix. By the incorporation of GO to create a nanocomposite, the $E$ and the $\sigma_{\max }$ dramatically increased compared with those of the PVA film. We compared the experimental $E$-value with the model prediction using the Halpin-Tsai equation. The experimental value remarkably exceeded the prediction at a low content of GO (under $1 \mathrm{wt} \%$ ). The excellent reinforcement of the nanocomposites was achieved by the strong interaction between PVA and GO. In addition, the barrier properties and the thermal properties of the nanocomposites remarkably increased when GO was incorporated. These property changes were largely attributed to the rigid structure of the GO sheets and their high aspect ratio. In conclusion, we succeeded in imparting not only the excellent properties of GO but also the advantageous effects derived from the sheet-like structure of GO effectively to the nanocomposites.

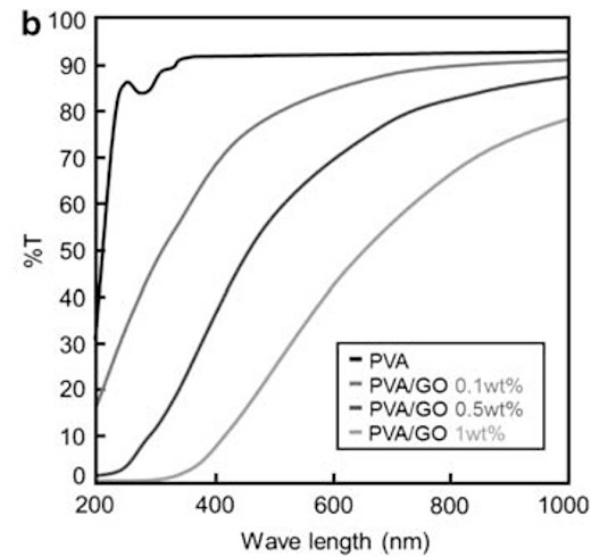

Figure 7 (a) Optical images of the PVA film and the PVA/GO nanocomposite; (b) ultraviolet-visible spectra of the PVA film and the PVA/GO nanocomposites. The thickness was $100 \mu \mathrm{m}$. A full color version of this figure is available at Polymer Journal online. 
1 Okada, A. \& Usuki, A. Twenty years of polymer-clay nanocomposites. Macromol. Mater. Eng. 291, 1449-1476 (2006).

2 Kojima, Y., Usuki, A., Kawasumi, M., Okada, A., Fukushima, Y., Karauchi, T. \& Kamigaito, 0. Mechanical properties of nylon-6/clay hybrid. J. Mater Res 8, 1185-1189 (1993).

3 Kojima, Y., Usuki, A., Kawasumi, M., Okada, A., Fukushima, Y., Karauchi, T. \& Kamigaito, 0 . Synthesis of nylon 6-clay hybrid by montmorillonite intercalated with E-caprolactam. J. Polym. Sci. 31, 983-986 (1993).

4 Kojima, Y., Usuki, A., Kawasumi, M., Okada, A., Fukushima, Y., Karauchi, T. \& Kamigaito, O. One-pot synthesis of nylon 6-clay hybrid. J. Polym. Sci. 31, 1775-1778 (1993).

5 Morimune, S., Kotera, M. \& Nishino, T. Stress transfer of poly (vinyl alcohol)/ montmorillonite nanocomposite using X-ray diffraction. J. Adh. Soc. Jpn. 46, 320-325 (2010).

6 Morimune, S., Kotera, M., Nishino, T., Goto, K. \& Hata, K. Poly(vinyl alcohol) nanocomposites with nanodiamond. Macromolecules 44, 4415-4421 (2011).

7 Tyler, T., Shenderova, O., Cunningham, G., Walsh, J., Drobnik, J. \& McGuire, G. Thermal transport properties of diamond-based nanofluids and nanocomposites.. Diam. Relat. Mater. 15, 2078-2081 (2006).

8 Khan, U., May, P., O'Neill, A. \& Coleman, J. N. Development of stiff, strong, yet tough composites by the addition of solvent exfoliated graphene to polyurethane. Carbon $\mathbf{4 8 ,}$ 4035-4041 (2010).

9 Paul, D. R. \& Robeson, L. M. Polymer nanotechnology: nanocomposites. Polymer 49, 3187-3204 (2008).

10 lijima, S. Helical microtubules of graphitic carbon. Nature 354, 56-58 (1991).

11 Baughman, R. H., Zakhidov, A. A. \& Heer, W. A. Carbon nanotubes- the route toward applications. Science 297, 787-792 (2002).

12 Masuda, J. \& Torkelson, J. M. Dispersion and major property enhancement in polymer/ multiwall carbon nanotube nanocomposites via solid-state shear pulverization followed by melt mixing. Macromolecules 41, 5974-5977 (2008).

13 Novoselov, K. S., Geim, A. K., Morozov, S. V., Jiang, D., Zhang, Y., Dubonos, S. V., Grigorieva, I. V. \& Firsov, A. A. Electric field effect in atomically thin carbon films. Science 306, 666-669 (2004).

14 Kotov, N. A. Materials science: carbon sheet solutions. Nature 442, 254-255 (2006).

15 Dikin, D. A., Stankovich, S., Zimney, E. J., Piner, R. D., Dommett, G. H., Evmenenko, B.G., Nguyen, S. T. \& Ruoff, R. S. Preparation and characterization of grapheneoxide paper. Nature 448, 457-460 (2007).

16 Avouris, P., Chen, Z. H. \& Perebeinos, V. Carbon-based electronics. Nat. Nanotechnol. 2, 605-615 (2007)

17 Kim, H., Abdala, A. A. \& Macosko, W. C Graphene/polymer nanocomposites. Macromolecules 43, 6515-6530 (2010).

18 Stankovich, S., Dikin, D. A., Dommett, G. H. B., Kohlhaas, K. M., E Zimney, J. E., Stach, A., Piner, R. D., Nguyen, S. T. \& Ruoff, R. S. Graphene-based composite materials. Nature 442, 282-286 (2006).

19 Stankovich, S., Dikin, D. A., Piner, R. D., Kohlhaas, K. A., Kleinhammes, A., Jia, Y. Wu, Y., Nguyen, S. T. \& Ruoff, R. S. Preparation and characterization of graphene oxide paper. Carbon 45, 1558-1565 (2007).

20 Navarro, C. G., Burghard, M. \& Kern, K. Elastic properties of chemically derived single graphene sheets. Nano Lett. 8, 2045-2049 (2008).

21 Watcharotone, S., Dikin, D. A., Stankovich, S., Piner, R., Jung, I., Dommett, G. H. B., Evmenenko, G., Wu, S. E., Chen, S. F., Liu, C. P., Nguyen, S. T. \& Ruoff, R. S. Graphene-silica composite thin films as transparent conductors. Nano Lett. 7, 1888-1892 (2007)

22 Liu, Z. F., Liu, Q., Huang, Y., Ma, Y. F., Yin, S. G., Zhang, X. Y., Sun, W. \& Chen, Y. S. Organic photovoltaic devices based on a novel acceptor material: graphene. Adv. Mater. 20, 3924-3930 (2008)

23 Wang, X., Zhi, L. J. \& Mullen, K. Transparent, conductive graphene electrodes for dyesensitized solar cells. Nano Lett. 8, 323-327 (2008).

24 Hummers, W. S \& Offeman, R. E . Preparation of graphitic oxide. J. Am. Chem. Soc. 80, 1339-1339 (1958).

25 Niyogi, S., Bekyarova, E., Itkis, M. E., McWilliams, J. L., Hamon, M. A. \& Haddon, R. C. Solution properties of graphite and graphene. J. Am. Chem. Soc. 128, 7720-7721 (2006).

26 Schniepp, H. C., Li, J. L., McAllister, M. J., Sai, H., Herrera-Alonso, M., Adamson, D. H., Prud'homme, R. K., Car, R., Saville, D. A. \& Aksay, I. A. Single graphene sheets derived from splitting graphite oxide. J. Phys. Chem. B. 110, 8535-8539 (2006).

27 McAllister, M. J., Li, J. L., Adamson, D. H., Schniepp, H. C., Abdala, A. A., Liu, J., Alonso, M. H., Milius, D. L., Car, R., Prud'homme, R. K. \& Aksay, I. A. Single sheet functionalized graphene by oxidation and thermal expansion of graphite. Chem. Mater. 19, 4396-4404 (2007)

28 Li, D., Muller, M. B., Gilje, S., Kaner, R. B. \& Wallace, G. G Processable aqueous dispersions of graphenenanosheets. Nat. Nanotechnol. 3, 101-105 (2008).

29 Si, Y. C. \& Samulski, E. T. Synthesis of water soluble graphene. Nano. Lett. 8, 1679-1682 (2008)

30 Zhang, W. D., Shen, L., Phang, I. Y. \& Liu, T. X. Carbon nanotubes reinforced nylon- 6 composite prepared by simple melt-compounding. Macromolecules 37, 256-259 (2004).

31 Coleman, J. N., Cadek, M., Blake, R., Nicolosi, V., Ryan, K. P., Belton, C., Fonseca, A., Nagy, J. B., Gun'ko, Y. K. \& Blau, W. J. High performance nanotube-reinforced plastics: understanding the mechanism of strength increase. Adv. Funct. Mater. 14, 791-798 (2004).

32 Liu, L. Q Barber, A. H. Nuriel, S. \& Wagner, H. D. Mechanical properties of functionalized single-walled carbon-nanotube/poly (vinyl alcohol) nanocomposites. Adv. Funct. Mater. 15, 975-980 (2005).

33 Begam, T., Nagpal, A. \& Singhal, R. A Comparative study of swelling properties of hydrogels based on poly(acrylamide-co-methyl methacrylate) containing physical and chemical crosslinks. J. Appl. Polym. Sci. 89, 779-786 (2003).

34 Barati, A., Norouzi, H., Sharafoddinzadeh, S. \& Davarnejad, R. Swelling kinetics modeling of cationicmethacrylamide-based hydrogels. World Appl. Sci. J. 11, 1336-1341 (2010).

35 Zhang, Q., Naito, K., Tanaka, Y. \& Kagawa, Y. Grafting polyimides from nanodiamonds. Macromolecules 41, 536-538 (2008).

36 Singh, V. K., Patra, M. K., Manoth, M., Gowd, G. S., Vadera, S. R. \& Kumar, N. In situ synthesis of graphene oxide and its composites with iron oxide. New Carbon Mater. 24, 147-152 (2009).

37 Yang, N., Zhai, J., Wan, M., Wang, D. \& Jiang, L. Layered nanostructures of polyaniline with graphene oxide as the dopant and template. Synthetic Metals 160, 1617-1622 (2010).

38 Kuznetsov, V. L. Study of ultradispersed diamond powders obtained using explosion energy. Carbon 29, 665-668 (1991)

39 Ozawa, M., Inaguma, M., Takahashi, M., Kataoka, F., Krüger, A. \& Osawa, E. Preparation and behavior of brownish clear nanodiamond colloids. Adv. Mater. 19, 1201-1206 (2007).

40 Lee, K., Bozoklu, G., Cai, W., Nguyen, S. T. \& Ruoff, R. S. Graphene oxide papers modified by divalent ions-enhancing mechanical properties via chemical cross-linking. ACS. Nano 2, 572-578 (2008).

41 Wang, H., Hao, Q., Yang, X., Lu, L. \& Wang, X. Effects of graphene oxide on the properties of its composite with polyaniline. ACS. Appl. Mater. Interfaces 2, 821-828 (2010).

42 Park, S., An, J., Piner, R. D., Jung, I., Yang, D., Valmakanni, A., Nguyen, S. T. \& Ruoff, R. S. Aqueous suspension and characterization of chemically modified graphene sheets. Chem. Mater. 20, 6592-6594 (2008).

43 Dubin, S., Gilije, S., Wang, K., Tung, V. C., Cha, K., Hall, A. S., Farrar, J., Varshneya, R., Yang, Y. \& Kaner, R. B. A. One-step, solvothermal reduction method for producing reduced graphene oxide dispersions in organic solvents. ACS. Nano 4, 3845-3852 (2010).

44 Xu, Y., Hong, W., Bai, H., Li, C. \& Shi, G. Strong and ductile poly(vinyl alcohol)/graphene oxide composite films with a layered structure. Carbon 47, 3538-3543 (2009).

45 Liang, J., Houng, Y., Zhang, L., Wang, Y., Ma, Y., Guo, T. \& Chen, Y. Molecular-level dispersion of graphene into poly(vinyl alcohol) and effective reinforcement of their nanocomposites. Adv. Funct. Mater. 19, 2297-2302 (2009).

46 Zhao, X., Zhang, Q., Chen, D. \& Lu, P. Enhanced mechanical properties of graphenebased poly(vinyl alcohol) composites. Macromolecules 43, 2357-2363 (2010).

47 Guth, E. Theory of filler reinforcement. J. Appl. Phys. 16, 20-25 (1985).

48 Halpin, J. C. \& Kardos, J. L. The Halpin-Tsai equations: a review. Polym. Eng. Sci. 16, 344-352 (1976).

49 Halpin, J. C Stiffness and expansion estimates for oriented short fiber composites. J. Comp. Mater. 3, 732-734 (1969).

50 Nielsen, L. E. Generalized equation for the elastic moduli of composite materials. J. Appl. Phys. 41, 4626-4627 (1970).

51 Lewis, T. B. \& Nielsen, L. E. Dynamic mechanical properties of particulated filler composites. J. Appl. Polym. Sci. 14, 1449-1471 (1970).

52 Wu, Y. P., Jia, Q. X., Yu, D. S. \& Qun, L. Modeling Young's modulus of rubber-clay nanocomposites using composite theories. Polym. Test. 23, 903-909 (2004).

53 Zhang, X., Liu, T., Sreekumar, T. V., Hu, X. \& Smith, K Gel spinning of pva/swnt composite fiber. Polymer 45, 8801-8807 (2004).

54 Vickery, J. L., Patil, A. J. \& Mann, S. Fabrication of graphene-polymer nanocomposites with higher-order three-dimensional architectures. Adv. Mater. 21, 2180-2184 (2009).

55 Sakurada, I. Polyvinyl Alcohol Fibers (Marcel Dekker, New York, 1985).

56 Wan, C., Zhang, Y. \& Zhang, Y. Effect of alkyl quaternary ammonium on processing discoloration of melt-intercalated pvc-montmorillonite composites. Polym. Test. 23, 299-306 (2004).

57 Zhou, T. H., Ruan, W. H., Rong, M. Z., Zhang, M. Q. \& Mai, Y. L. Keys to toughening of non-layered nanoparticles/polymer composites. Adv. Mater. 19, 2667-2671 (2007).

58 Lee, C., Leigh, D. A., Pritchard, R. G., Schultz, D., Teat, S. J., Timco, G. A. \& Winpenny, R. E. P. Hybrid organic-inorganic rotaxanes and molecular shuttles. Nature 458, 314-318 (2009).

59 Jiang, L., Shen, X. P., Wu, J. L. \& Shen, K. C. Preparation and characterization of graphene/poly(vinyl alcohol) nanocomposites. J. Appl. Polym. Sci. 118, 275-279 (2010).

60 Nishino, T., Meguro, M. \& Nakamae, K. Poly(vinyl alcohol) with low surface free energy by fluorination. Int. J. Adhes. Adhes. 19, 399-403 (1999).

61 Abdrashitov, E., Bokun, V., Kritskaya, D. \& Ponomarev, A. Investigation of poly(vinylidene chloride) distribution in perfluorinated cation-exchange membranes mf-4sk upon uv- and $\gamma$-initiated graft polymerization. High Energy Chem. 42, 419-425 (2008).

62 Podsiadlo, P., Kaushik, A. K., Arruda, E. M., Waas, A. M., Shim, B. S., Xu, J., Nandivada, H., Pumplin, B. G., Lahann, J., Ramamoorthy, A. \& Kotov, N. A. Ultrastrong and stiff layered polymer nanocomposites. Science 318, 80-83 (2007). 